\title{
Homo informaticus: Thinking and moral values of humans are shaped by human-computer-interaction
}

\author{
Michael Trimmel* \\ Center for Public Health, Institute for Environmental Health and Environmental Medicine, Medical University of Vienna, Kinderspitalgasse 15, A 1090 Vienna, \\ Austria
}

\begin{abstract}
Human-computer-interaction (HCI) including social networking and gaming rose fast and is now part of the society. Besides the technological innovations initiated and implemented by humans, another impact, namely that HCI modifies the way of human thinking and changes human motivation and personality by a shift of moral values was proposed and was summarized in the concept of Homo informaticus. Experimental and theoretical evidence suggest that Homo informaticus can be described as characterized by (1) altered perception, (2) mental load and distorted memory formation, (3) altered thinking, (4) reduced sense of reality, (5) preference of hierarchy, (6) low conscientiousness, (7) a motivational shape by shifted moral values towards power and egoism, (8) altered social interaction, (9) risk of problematic technology usage or even technology addiction, (10) some technology competence, and (11) humans acting as an information technology (computer) subsystem.
\end{abstract}

At the moment "The VIENNA BIENNALE (2017) Robots. Work. Our Future focuses on the potential of art, design, and architecture to contribute to an environmentally and socially sustainable concept of the digital age that is also committed to a new humanism" [1]. This topic is driven by the view that digital utopic concepts - like autonomous driving, drone delivering, detailed analyses of Internet users and customers - have been realized faster than one would have imagined only a few years ago. Such technological changes are often seen as a manifestation of human progress, driven by needs and implemented through human creativity. However, the opposite view, namely that technological progress, in particular expressed in extensive humancomputer-interaction (HCI) and connectedness (Internet), may shape human thinking and moral values, could also be considered.

The last view is supported by early experimental work investigating effects of HCI on higher cognitive functions. In those experiments, immediate effects of $\mathrm{HCI}$ as compared to paper/pencil tasks were observed. All test persons displayed less field dependency - a cognitive style related to the integration of the actual environment in the process of perception [2] - after HCI [3]. HCI also affected causal attribution (the kind of how persons explain the causes of events and actions $[4,5]$ ) in that way that test persons attributed less internally (meaning that they are less personally responsible) in the field of "intellectual thinking" but attributed more externally (in the sense of "luck or bad luck") for human relationships after HCI compared to the control condition [6]. Other experimental effects were observed for interference tendency, the interference of different memory traces during the transition into the long-term memory [7], where non-computer-science-students had a higher interference tendency after HCI than computer-sciencestudents [3], and also in communication style, where computerscience-students preferred a verbal expression of abstract concepts to a pantomimic expression contrary to non-computer-science-students [8]. Moreover, comparing computer-science-students with noncomputer users (as had been possible in those days), comparable effects to the immediate experimental effects were observed and interpreted as long-lasting effects of HCI [3,8]. Thus, there is some evidence that HCI immediately affects higher cognitive functions and persons with an extensive amount of HCI may display such characteristics in general.

In addition to effects of HCI on higher cognitive functions also a cardiovascular activation during $\mathrm{HCI}[9,10]$ and neurophysiological after-effects of HCI were observed [11]. The comparison of the P300 of event-related brain potentials [12] after HCI versus paper/ pencil activity indicates less mental resources after HCI, as the P300 amplitude was generally reduced after HCI. Another indication that HCI affects human resources was demonstrated by an accelerated heart rate during prolonged response times of Internet search [10]. In this study, it was also shown that persons feeling high strain displayed a rather high mean heart rate of $114 \mathrm{bpm}$ during long ( 22 s) waiting times and a mean heart rate of $93 \mathrm{bpm}$ for short waiting times $(\sim 2 \mathrm{~s})$, contrary to persons without strain displaying a mean heart rate of 85 bpm independent of waiting time during an Internet search.

Through the rise of the Internet, HCI is now dominated by Internet activity with extensive activity in social networks and gaming. As already pointed out in the early rise of computer games, the problematic Internet usage arises in parallel $[8,9]$. This may be forced by the emotional engagement as indicated by the relative strong response in the cardiovascular system in general and cognitive-motivational factors in addition. In particular the flow-theory [13] gives a useful

Correspondence to: Michael Trimmel, Center for Public Health, Institute for Environmental Health and Environmental Medicine, Medical University of Vienna, Kinderspitalgasse 15, A 1090 Vienna, Austria, E-mail: michael.trimmel@ meduniwien.ac.at

Key words: human-computer-interaction, social networking, gaming, motivation, moral values, cognition, perception, thinking, personality, behaviour, problematic technology usage, cyberbullying

Received: June 12, 2017; Accepted: June 26, 2017; Published: June 29, 2017 
frame on the motivation and on the subjective experience of computer gaming $[9,11]$. Meanwhile this view was supported by recent data and interpreted as the "Janus-faced role of gambling flow" [14]. Moreover, numerous reports and different investigations on problematic Internet usage [15] and Internet addiction can be found in the literature, and seem of particular interest from a public health, social, and educational point of view, because there are concerns about the long-lasting consequences for society in general.

Thus, it seems reasonable to consider how HCI (including social networking and gaming) in general may affect human behavior by changing human thinking and changing human moral values which are essential elements of motivation and decision making. This was already considered by early observations on how behavior was altered due to $\mathrm{HCI}$ as described by Weizenbaum [16] and by integrating experimental results of that time (1998) to the construct of Homo informaticus [6]. An update was presented 2015 [17] with new supporting data, in particular considering aspects of personality and moral values from a cross sectional study of 396 persons (mean age $37 \mathrm{y}, 213$ females). According to personality, it was shown that Internet usage (as indicated by the Facebook intensity score, FBI [18]) is associated positively with extraversion, but negatively with conscientiousness [17]. The relationship of Internet usage (FBI) with moral values (portraits value questionnaire, PVQ [19]) indicates that FBI is correlated positively with hierarchy, mastery, affective autonomy, intellectual autonomy and negatively correlated with harmony. Although some relationships as intellectual autonomy and social value may be considered as a positive progress, others, in particular hierarchy and less harmony may be considered as less positive for society and the future.

These data support earlier observations that HCI and Internet activity may affect higher cognitive functions and by this personality and motivation and, at last, behavior. Although there are contributions underpinning positive effects of Internet usage, most often expressed in the sense of competence or social values, analyses of the impact on thinking and of moral values seem to support a critical view of the Homo informaticus - a summarizing conception on how humans and society in general are shaped by the use of modern information technology - with the proposed cognitive, motivational, and behavioral features: (1) altered perception, (2) mental load and memory formation distortion, (3) altered thinking, (4) reduced sense of reality, (5) preference of hierarchy, (6) low conscientiousness, (7) a motivational shape by shifted moral values towards power and egoism, (8) altered social interaction, (9) risk of problematic technology usage or even technology addiction, (10) some technology competence, and (11) humans acting as an information technology (computer) subsystem.

These characteristics of the proposed Homo informaticus are further supported by (other) empirical evidence and theoretical issues:

(1) Altered perception. As pointed out in an early work [3], HCI reduces the impact of the actual social and physical environment in the process of perception as indicated by a reduced field dependency. One may speculate that this is caused by attention processes to avoid information overload as already described for noise environments [20], in which environmental information is filtered out by attention switching.

(2) Mental load and a distorted memory consolidation may also be caused by a high information processing load and attentional affordances (as described above). Early observations of memory consolidation were indicated by a high interference tendency as an expression of a reduced memory consolidation to represent information in the longterm memory, after HCI [3]. Moreover, as indicated by a reduced P300 amplitude of the event-related brain potential [12], mental resources are reduced after HCI [11]. In addition to that observations a highly "synchronized" P300-latency across recording locations was observed; such a timely synchronized mental activity at various brain areas may speculatively be interpreted as an expression of a "less modular activity of mind" [21] caused by HCI and the associated mental demands. Another source of emotional load is predominant in social networking sites by reason of maintaining existing relationships, developing of new contacts [22-25] and depends on how selfpresentation is perceived individually, for which personality aspects of narcissism and self-esteem are important moderators [26,27].

(3) Altered thinking was already indicated by early observations of causal effects of HCI on attribution style, that is the way how realworld causalities are interpreted by a person [5]. The enhanced internal attribution for the fields of work and of computer [3] are in line with an aspect driven by egoism in the information technology [17]. But this aspect is not independent from other (motivational) aspects like preference of hierarchy and motives towards power and egoism (see below).

(4) Preference of hierarchy is indicated by the positive correlation of FBI with a preference of hierarchy (as indicated by the PVQ [19]).

(5) A reduced sense of reality was observed by analysing the content of stories written after HCI contrary to stories written after comparable paper/pencil tasks [28].

(6) The association with low values of conscientiousness is supported by the inverse correlations of FBI with conscientiousness (as indicated by the PVQ [19]) and is also found in recent studies $[29,30]$ and furthermore supported by a negative correlation with harmony [17].

(7) An enhanced motivation towards power and egoism as indicated by the correlation of FBI with the PVQ [19] is closely related to the aspects mentioned above, namely preferring hierarchy and displaying low conscientiousness.

(8) Altered social interaction is indicated by a number of observations. Early causal effects were observed for a reduced conversation style of pantomimic expression of an abstract concept after HCI. This may speculatively be interpreted as a reduced preference of an "analogous" contrary to a "digital" communication style as in the case of a verbal description. Another aspect of social interaction is often reported by the association of Internet usage, in particular social network activities, with extraversion and introversion, whereby extraverts use social network sites for social enhancement and introverts use it for social compensation [29]. Moreover, for persons with high social network usage high values in narcissism associated with a decreased real life social community participation and relational problems were reported [29] and their behavior is sometimes associated with problematic Internet usage including cyberbullying [31]

(9) The risk of "information technology addiction", which includes social network activity and gaming, has been described since the early years. One aspect of information technology is the aspect of a very high interactivity, which may be perceived as a human-to-human interaction as has already been described in 1976 by Weizenbaum [16] and later [6]. Such a highly interactive communication may be perceived like a communication with an idealized partner, and would therefore have a high potential to prolong this (digital) "interaction" 
with no risk of being confronted with "real life". Another mechanism often described as a highly motivating aspect is the conception of "flow" [13]. In particular in the context of computer gaming, but also for other activities on the computer/Internet, the characteristic trait is that the specific claims can be user-adjusted and therefore be determined in a close match to the capability of the person, thus provoking the experience of flow as suggested [6,9] which was also described for Facebook [32]. However, for problematic Internet usage and Internet addiction neither the high interactivity nor flow experience could satisfactorily explain this problem, but life satisfaction was identified as a moderating background variable [33] and psychopathological variables including personality traits like autistic fantasy and non-adaptive coping strategies and depressive symptoms are discussed as underlying mechanisms [34]. One of the rising problems of excessive Internet usage is that such a behavior is also prevalent in children, of which $20 \%$ displayed a risk for psychosocial problems [35], moreover, it was shown that for smartphone addiction traditional interventions failed [36]. For massive multiplayer online role-playing games players maladaptive personality traits like schizotypal personality traits were identified [37].

(10) Some technology competences are described as positive effects of (extensive) HCI or of social network usage. Investigating the relationship of Facebook use and the social capital it was found that intensity of Facebook was related to life satisfaction, social trust, civic engagement, political participation [38], higher motivation [39], and also to psychological well-being [18], whereas others found contradictory results on the association of social networking with individual welfare [40]. However, from a critical point of view, there are also reports on the subjective overestimation of competences discussed as the Dunning-Kruger effect [41,42] and there are also reports of decreased academic achievement associated with social networking [29].

(11) Humans acting as a subsystem of information technology (computers). Although this aspect can be seen as a separate characteristic of the Homo informaticus, it is also a "general" characteristic including the claims made in (1)-(10). As people became more and more educated and confronted with information technology their "mental set" [43-45] will be shaped more and more by changes in perception, thinking, decision making and motivation towards the inclusion of information technology - even if this was not necessary or might be counterproductive. Such implications of mental sets on the unknowingly undertaken limitation of the space where designers search for solutions was recently demonstrated experimentally [46]. Moreover, humans perceive the social and physical environment in a way that it can be incorporated into information technology, thus, humans are acting like a subsystem of the information technology.

\section{References}

1. Vienna Biennale. The first Biennale for art, design, and architecture 2017. Available from: http://www.viennabiennale.org/en/calendar/event/eroeffnung-vienna-biennale-2017/.

2. Witkin HA, Dyk RB, Fattuson HF, Goodenough DR, Karp SA (1962) Psychological differentiation: Studies of development. Oxford, England: Wiley.

3. Trimmel M, Brand M, Chmelik R, Ewald A, Froeschl KA, Huber R, et al. (1993) Psychological and psychophysiological effects of working with computers: Experimental evidence. In: Luczak H, Cakir A, Cakir G, editors. Work With Display Units 92. Amsterdam: Elsevier Science Publishers B.V.;121-128.

4. Heider F (1944) Social perception and phenomenal causality. Psychological Review 51: $358-374$.

5. Rotter JB (1966) Generalized expectancies for internal versus external control of reinforcement. Psychological Monographs 80: 1-28.[Crossref]

6. Trimmel M (1998) Homo Informaticus - der Mensch als Subsystem des Computers. In: Kolb A, Esterbauer R, Ruckenbauer H-W, editors. Cyberethik Verantwortung in der digital vernetzten Welt. Stuttgart: W. Kohlhammer; 96-114.
7. Müller GE, Pilzecker A (1900) Experimentelle Beiträge zur Lehre vom Gedächtnis. Zeitschrift für Psychologie, Ergänzungsband 1: 1-300.

8. Trimmel M (1992) Auswirkungen der Mensch-Computer-Interaktion: psychologische Aspekte. Informatik Forum 6: 194-202.

9. Trimmel M (1996) Bedingungen des Computerspiels und psychologische Auswirkungen bei Jugendlichen. Informatik Forum 10: 215-234.

10. Trimmel M, Meixner-Pendleton M, Haring S (2003) Stress response caused by system response time when searching for information on the internet. Human Factors 45: 615622. [Crossref]

11. Trimmel M, Huber R (1998) After-effects of human-computer interaction indicated by P300 of the event-related brain potential. Ergonomics 41: 649-655. [Crossref]

12. Trimmel M (1990) Angewandte und Experimentelle Neuropsychophysiologie. Heidelberg: Springer.

13. Csikszentmihalyi M (1975) Beyond boredom and anxiety - the experience of play in work and games. San Francisco: Jossey-Bass Publishers

14. Trivedi RH, Teichert $\mathrm{T}$ (2017) The Janus-faced role of gambling flow in addiction issues. Cyberpsychology, Behavior, and Social Networking 20: 180-186.[Crossref]

15. Bauernhofer K, Papousek I, Fink A, Unterrainer HF, Weiss EM (2016) Problematic internet use (PIN) - a review of assessment questionnaires and risk factors. Neuropsychiatrie 30: 2-9.[Crossref]

16. Weizenbaum J (1976) Computer power and human reason: From judgment to calculation. San Francisco: Freeman.

17. ISIS. Summit Vienna 2015 - The Information Society at the Crossroads [2017-06-21] Available from: https://sciforum.net/conference/isis-summit-vienna-2015.

18. Ellison NB, Steinfield C, Lampe C (2007) The benefits of facebook "Friends:" Social capital and college students' Use of online social network sites. Journal of ComputerMediated Communication 12: 1143-1168.

19. Schwartz SH (1992) Universals in the content and structure of values: Theoretical advances and empirical tests in 20 countries. Advances in Experimental Social Psychology 25: 1-65.

20. Trimmel K, Schätzer J, Trimmel M (2014) Acoustic noise alters selective attention processes as indicated by direct current (DC) brain potential changes. International Journal of Environmental Research and Public Health 11: 9938-9953.[Crossref]

21. Fodor JA (1983) The modularity of mind. Cambridge, MA: MIT Press.

22. Tokunaga RS (2011) Friend me or you'll strain us: understanding negative events that occur over social networking sites. Cyberpsychology, Behavior, and Social Networking 14: 425-432.[Crossref]

23. Manner C, Blakley S, Lawrence S, O’Neill E, Raines C (2011) Understanding the predictors of negative personal relationship experiences on facebook. International Journal of Humanities and Social Science 1: 16-19.

24. Lyndon A, Bonds-Raacke J, Cratty AD (2011) College students' facebook stalking of ex-partners. Cyberpsychology, Behavior, and Social Networking 14: 711-716. [Crossref]

25. Marder B, Joinson A, Shankar A (2012) Every post you make, every pic you take, I'll be watching you: Behind social spheres on Facebook. 45th Hawaii International Conference on System Science (HICSS), 2012: IEEE;859-868.

26. Mehdizadeh S (2010) Self-presentation 2.0: narcissism and self-esteem on Facebook Cyberpsychology, Behavior, and Social Networking 13: 357-364. [Crossref]

27. Gonzales AL, Hancock JT (2011) Mirror, mirror on my Facebook wall: effects of exposure to Facebook on self-esteem. Cyberpsychology, Behavior, and Social Networking 14: 79-83.

28. Trimmel M (1994) Computertätigkeit und Realitätsbezug. In: Janig H, editor Psychologische Forschung in Österreich. Klagenfurt: Universitätsverlag Carinthia; 224-228.

29. Kuss DJ, Griffiths MD (2011) Online social networking and addiction--a review of the psychological literature. International Journal of Environmental Research and Public Health 8: 3528-3552.[Crossref]

30. Light B, McGrath K (2010) Ethics and social networking sites: a disclosive analysis of Facebook. Information Technology and People 23: 290-311.

31. Park S, Na E-Y, Kim E-M (2014) The relationship between online activities, netiquette and cyberbullying. Children and Youth Services Review 42: 74-81.

32. Mauri M, Cipresso P, Balgera A, Villamira M, Riva G (2011) Why is Facebook so successful? Psychophysiological measures describe a core flow state while using Facebook. Cyberpsychology, Behavior, and Social Networking 14: 723-731.[Crossref] 
33. Longstreet P, Brooks S (2017) Life satisfaction: A key to managing Internet and social media addiction. Technology in Society 50: 73-77.

34. Laconi S, Vigouroux M, Lafuente C, Chabrol H (2017) Problematic internet use, psychopathology, personality, defense and coping. Computers in Human Behavior 73 $47-54$

35. Işik B, Ayaz Alkaya S (2017) Internet use and psychosocial health of school aged children. Psychiatry Research 255: 204-208.[Crossref]

36. Lee S-J, Lee C (2016)Smartphone addiction and application usage in Korean adolescents: Effects of mediation strategies. Social Behavior and Personality 44: 1525-1534.

37. Schimmenti A, Infanti A, Badoud D, Laloyaux J, Billieux J (2017) Schizotypal personality traits and problematic use of massively-multiplayer online role-playing games (MMORPGs). Computers in Human Behavior 74: 286-293.

38. Valenzuela S, Park N, Kee KF (2009) Is there social capital in a social network site? Facebook use and college students' life satisfaction, trust, and participation. Journal of Computer-Mediated Communication 14: 875-901.

39. Trimmel M, Bachmann J (2004) Cognitive, social, motivational and health aspects of students in laptop classrooms. Journal of Computer Assisted Learning 20: 151-158.
40. Sabatini F, Sarracino F (2014) Online networks and subjective well-being. Köln: GESIS - Leibniz-Institut für Sozialwissenschaften.

41. Kruger J, Dunning D (1999) Unskilled and unaware of it: How difficulties in recognizing one's own incompetence lead to inflated self-assessments. Journal of Personality and Social Psychology 77: 1121-1134. [Crossref]

42. Gibbs S, Moore K, Steel G, McKinnon A (2017) The Dunning-Kruger effect in a workplace computing setting. Computers in Human Behavior 72: 589-595.

43. Vallée-Tourangeau F, Euden G, Hearn V (2011) Einstellung defused: Interactivity and mental set. The Quarterly Journal of Experimental Psychology 64: 1889-1895.[Crossref]

44. Ellis JJ, Reingold EM (2014) The Einstellung effect in anagram problem solving: evidence from eye movements. Frontiers in Psychology 5: 679. [Crossref]

45. Luchins AS (1942) Mechanization in problem solving: The effect of Einstellung Psychological Monographs 54: i-95.[Crossref]

46. Neroni MA, Vasconcelos LA, Crilly N (2017) Computer-based “mental set” tasks: An alternative approach to studying design fixation. Journal of Mechanical Design 139: 071102 .

Copyright: (C2017 Trimmel M. This is an open-access article distributed under the terms of the Creative Commons Attribution License, which permits unrestricted use, distribution, and reproduction in any medium, provided the original author and source are credited. 